\title{
IN SITU, REAL-TIME STUDIES OF FILM GROWTH PROCESSES USING ION SCATTERING AND DIRECT RECOIL SPECTROSCOPY TECHNIQUES*
}

V. S. Smentkowski1, A. R. Krauss ${ }^{2}$, O. Auciello 3 , J. Im $^{3}$, D. M. Gruen ${ }^{2}$, J. Holecek ${ }^{4}, K$. Waters ${ }^{4}$, and J. A. Schultz ${ }^{4}$

1GE Corporate Research and Development Center, Schenectady, NY 12301. Tel: 518-387-5467, Fax: 518-387-6972, e-mail: smentkow@crd.ge.com

2Materials Science and Chemistry Divisions, Argonne National Laboratory, Argonne, II 60439 ${ }^{3}$ Materials Science Division, Argonne National Laboratory, Argonne, II 60439

${ }^{4}$ Ionwerks, Houston, TX 77005

submitted for publication in the

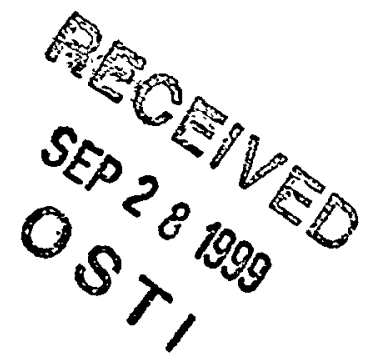

Proceedings of the "In Situ Process Diagnostic and Modeling" Symposium, Materials Research Society Meeting, San Francisco, California April 5-9, 1999

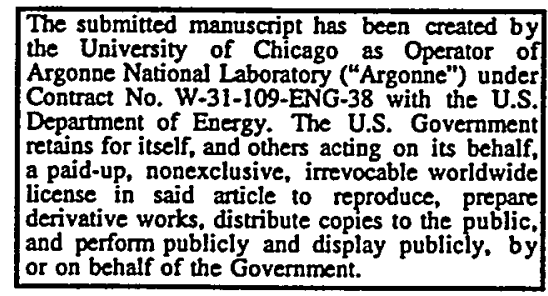

*Work supported by the U.S. Department of Energy, BES-Materials Sciences, under Contract W-31-109-ENG-38, and ER-LTR CRADA \#C9405001. 


\section{DISCLAIMER}

This report was prepared as an account of work sponsored by an agency of the United States Government. Neither the United States Government nor any agency thereof, nor any of their employees, make any warranty, express or implied, or assumes any legal liability or responsibility for the accuracy, completeness, or usefulness of any information, apparatus, product, or process disclosed, or represents that its use would not infringe privately owned rights. Reference herein to any specific commercial product, process, or service by trade name, trademark, manufacturer, or otherwise does not necessarily constitute or imply its endorsement, recommendation, or favoring by the United States Government or any agency thereof. The views and opinions of authors expressed herein do not necessarily state or reflect those of the United States Government or any agency thereof. 


\section{DISCLAIMER}

Portions of this document may be illegible in electronic image products. Images are produced from the best available original document. 


\title{
IN SITU, REAL-TIME STUDIES OF FIM GROWTH PROCESSES USING ION SCATTERING AND DIRECT RECOIL SPECTROSCOPY TECHIIQUES
}

\author{
V.S. SMENTKOWSKI ${ }^{1}$, A. R. KRAUSS ${ }^{2}$, O. AUCIELLO ${ }^{3}$, J. IM ${ }^{3}$, \\ D.M. GRUEN ${ }^{2}$, J. HOLECEK ${ }^{4}$, K. WATERS ${ }^{4}$, J. A. SCHULTZ ${ }^{4}$.
}

'GE Corporate Research and Development Center, Schenectady, NY 12301. Tel: 518-3875467, Fax: 518-387-6972, e-mail: smentkow@crd.ge.com

${ }^{2}$ Materials Science and Chemistry Divisions, Argonne National Laboratory, Argonne, II 60439

${ }^{3}$ Materials Science Division, Argonne National Laboratory, Argonne, Il 60439

${ }^{4}$ Ionwerks, Houston, TX 77005

\begin{abstract}
Time-of-flight ion scattering and recoil spectroscopy (TOF-ISARS) enables the characterization of the composition and structure of surfaces with 1-2 monolayer specificity. It will be shown that surface analysis is possible at ambient pressures greater than $3 \mathrm{~m}$ Torr using TOF-ISARS techniques; allowing for real-time, in situ studies of film growth processes. TOF-ISARS comprises three analytical techniques: ion scattering spectroscopy (ISS), which detects the backscattered primary ion beam; direct recoil spectroscopy (DRS), which detects the surface species recoiled into the forward scattering direction; and mass spectroscopy of recoiled ions (MSRI), which is a variant of DRS capable of isotopic resolution for all surface species - including $\mathrm{H}$ and $\mathrm{He}$. The advantages and limitations of each of these techniques will be discussed.

The use of the three TOF-ISARS methods for real-time, in situ film growth studies at high ambient pressures will be illustrated. It will be shown that MSRI analysis is possible during sputter deposition. It will be also be demonstrated that the analyzer used for MSRI can also be used for time of flight secondary ion mass spectroscopy (TOF-SIMS) under high vacuum conditions. The use of a single analyzer to perform the complimentary surface analytical techniques of MSRI and SIMS is unique. The dual functionality of the MSRI analyzer provides surface information not obtained when either MSRI or SIMS is used independently.
\end{abstract}

\section{INTRODUCTION AND BACKGROUND}

Complex thin films are often deposited, following a standard protocol (recipe) in processing environments, without any in situ analysis. Periodically, samples are transferred through ambient air into surface analytical instrumentation for analysis. The use of real-time, in situ, monitoring would allow the characterization of the surface of thin films during growth. The information obtained from real-time, in situ monitoring could be used to modify the deposition process, such that films with the required properties (composition, phase, etc) are reliably produced. Real-time, in situ monitoring and control could, in principle, decrease the failure rate to zero. Real-time, in situ analysis requires a technique that can operate at high ambient pressures, be non-destructive, should provide a wide range of surface compositional and structural information on a time scale commensurate with the deposition rate, and must be compatible with the geometric constraints of the deposition process. 
Ion scattering spectroscopy (ISS) has becn used for surfacc analysis for a number of years [1-5]. For ISS, an energetic primary ion beam is directed onto a surface at near normal incidence as shown in Figure 1. The backscattered ions lose energy according to classical two body collision kinematics; the energy of the backscattered ions correlates with the mass of the surface atoms. ISS is ablc to detect all elements heavier than the primary ion [1-5]. In its infancy, ISS was performed using electrostatic (hemispherical) energy analyzers. There are three limitations of electrostatic energy analyzers: (1) they only detect the positive ion fraction, which is typically about $10^{-2}$ to $10^{-4}$ of the scattered primary beam; (2) they transmit only a narrow portion of the energy distribution; and (3) electrostatic energy analyzers are bulky and would interfere with thin film deposition equipment. Large beam doses are required in order to circumvent the low detection efficiency of electrostatic energy analyzers (limitations 1 and 2 above). The advent of time of flight (TOF) detection drastically changed ion scattering spectroscopy $[6,7]$. Since TOF detection simultaneously measures the total sputtered yield (ion plus neutral), the data acquisition time is significantly less. Additionally, TOF analyzers are smaller than electrostatic analyzers and could be incorporated into thin film deposition systems.

A limitation of ISS is that only elements heavier than the primary ion are detected. Light weight species, such as H, D, and He can not be detected, even if a He primary ion beam is used. In 1975, Buck et. al, demonstrated that if the primary ion beam strikes the surfacc at glancing incidence, and if a time of flight detector is positioned in the forward scartering direction (glancing exit angle, see Figures 1 and 2), one can directly detect the species that are ejected from the surface [6,7]; the technique is called direct recoil spectroscopy (DRS) [5-12].

DRS is able to detect all surface species [5-14]. DRS has been used to study the interaction of $\mathrm{H}$ as well as $\mathrm{D}$ with $\mathrm{Si}[13]$ and diamond $[10,11,14]$. DRS peaks are broad since: (1) the binary primary ion/substrate collisions are not ideal, and (2) multiple scattering events occur. The broad peaks degrade the resolution and also prevents the detection of species present in small quantities. If the ionic fraction of the sputtered particles are diverted into a time refocusing analyzer such as a Poschenreider sector [15]or a reflectron [16,17], one can obtain isotopically resolved mass spectra of the species present on the surface $[8,9,17-19]$. The use of a time refocusing analyzer to improve the resolution of the DR spectra is referred to as mass spectroscopy of recoiled ions (MSRI). MSRI has two advantages over DRS, increased resolution and increased sensitivity $[8,9,1,17-19]$.

The three complementary ion scattering techniques ISS, DRS, and MSRI are collectively referred to as time of flight ion scattering and recoil spectroscopy (TOF-ISARS).

\section{ION SCATTERING METHODOLOGY AND THEORY}

Figure I shows the concepts leading to signal generation for the three TOF-ISARS methods. A pulsed ion beam of mass $M_{0}$ and with a kinetic energy $\left(E_{0}\right)$ of $5 \mathrm{keV}$ to $15 \mathrm{keV}$ strikes the surface to be studied. At these high energies, the collision kinematics are essentially those of classical two body elastic collisions. The energetics of the binary collision results in complete decomposition of the molecular species present on the surface. The three analytical methods differ in the geometry of the incident ion beam $(\alpha)$ and the detectors $(\theta)$ as shown in Figure 2. In Figure 2, and throughout this text, the subscripts $i$ and $r$ referrer to ISS and DRS/MSRI respectively.

For ISS, $\alpha_{i}$ is about $90 \mathrm{deg}$ and $\theta_{\mathrm{i}}$ is about $180 \mathrm{deg}$ as shown in Figure 2. ISS is a well established surface analytical technique that has been used to study the composition and 
structure of many materials [1-6]. The sampling depth of ISS is only one to two layers. ISS is therefore the most surface sensitive analytical technique available. ISS is often used to determine if thin films are growing in a layer by layer fashion, a 2D fashion, or a 3D island nucleation fashion [20,21]. Additional information on ISS can be found in the literature [1-6, 20,21].

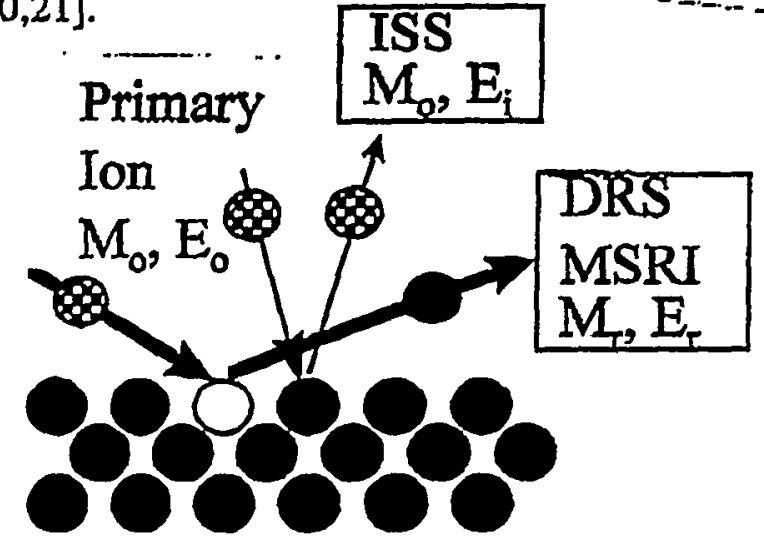

Figure 1. Schematic of the three TOP-ISARS processes: ISS, DRS, and MSRI.

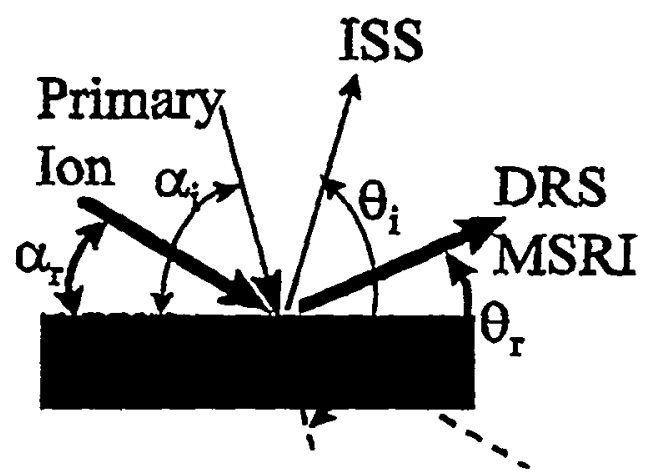

Figure 2. Definition of the angles for the three TOF-ISARS processes.

For both DRS and MSRI the pulsed ion beam strikes the surface at grazing incidence $\left(\alpha_{r}\right)$. The binary collision results in the direct ejection of the surface species in the forward scattering direction. DRS and/or MSRI analyzers are positioned at grazing exit angles $\left(\theta_{f}\right)$ as shown in Figures 2 and 3. The kinetic energy of the ejected atoms $\left(\mathbb{E}_{x}\right)$ is given by:

$$
E_{\tau}=4 E_{0} M_{0} M_{r} \operatorname{Cos}^{2} \theta_{r} /\left(M_{0}+M_{r}\right)^{2}
$$

where $M_{0}$ and $M_{r}$ are the masses of the primary ion and the surface atoms respectively, $E_{0}$ is the energy of the primary jon, and $\theta_{r}$ is the exit angle (shown in Figure 2). The values obtained from equation (1) are only valid for an ideal binary collision. Deviations from ideal conditions (i.e., multiple collisions) result in the loss of energy and as a result, each mass has a kinetic energy spread, and not a unique single value. The energy spread results in the broadening of the DRS features towards longer flight times and limits the mass resolution obtained using DRS. The spread in kinetic energy of the recoiled ions can be compensatcd by diverting the ion fraction into a reflectron time refocusing analyzer [15-16]. For ions of a given mass, the higher kinetic energy ions travel far into the reflectron before being turned around while the less energetic ions do not penetrate as deeply and therefore travel a shorter distance [15-19]. By properly adjusting the reflectron potentials and experimental geometry, all ions of a given mass are forced to arrive at the detector simultaneously; enhancing the resolution. The use of a time refocusing analyzer to improve the resolution of DR spectra is referred to as mass spectroscopy of recoiled ions (MSRI) $[8,9,17-19]$. MSRI is capable of both isotopic resolution for the entire mass range and better than part per million (ppm) sensitivity [17].

If is of importance to point out the difference between secondary ion mass spectroscopy (SIMS) and MSRI. The hardware used for MSRI is similar to that used for TOF-SIMS. For MSRI, the geometry is chosen to emphasize single collision ejection events rather than the multiple collision cascade mechanism associated with the SIMS process $[22,23]$. Both the kinetic energy and the ion fraction of the ejected surface atoms are much 
higher for MSRI than SIMS. In SIMS, the atoms are ejected close to the sample normal as a result of a cascade of numerous small angle collisions between the recoiling target atoms (i.e. collision cascade) $[22,23]$ rather than between the primary ion and the target atom. By the time a surface atom receives enough momentum from the cascade to be ejected normally from the surface, the kinetic energy has degraded to only a feweV $[22,23]$. The sputtered specics leave the surface with only a few eV of energy; regardless of the primary ion energy. The low energy SIMS atoms ejected from the surface have a significant amount of time during which charge exchange can occur between the surface and the departing atoms, resulting in a high degree of charge neutralization of the sputtered atoms [22]. The amount of charge neutralization changes drastically as the surface composition changes. In SIMS, the ion fraction is low (typically only $10^{-2}$ to $10^{-5}$ ); as the composition of the surface changes, the ion yield can vary by up to five orders of magnitude; this is the well known SIMS "matrix effect" [22]. In contrast to SIMS, the sputtered species in DRS/MSRI leave the surface with much greater energies (see equation 1) [8,9,17-19], and are not as prone to charge neutralization with the surface. As a result, the ion fraction of the direct recoil atoms often exceed $10 \%$ and in many cases approaches $100 \%$ [24]. In contrast to MSRI, both elemental species and molecular fragments are detected in SIMS. The SIM spectra can be difficult to interpret.

High energy sputtered particles are detected using the three TOF-ISARS techniques. It has been shown that high energy particles can travel through short, high pressure, paths [10]. If the experimental apparatus is properly configured (e.g., differential pumping apertures are placed on the end of the primary ion beam column and the entrance to the detectors, and thesc regions are differentially pumped), the three TOF-ISARS techniques are capable of surface analysis at high ( $>3 \mathrm{~m}$ Torr) ambient pressures, as will be shown below. ISS, DRS, and MSRI can therefore be used for real-time, in situ analysis of thin film growth [8,9]. Collision cross sections have been measured for ISS and DRS [25,26], as well as MSRI [27] and the values obtained are consistent with $\mathrm{Ar}^{+} / \mathrm{Ar}$ momentum transfer cross section values reported in the literature [28].

\section{EXPERIMENTAL}

The experiments reported here were performed in two ultra-high vacuum chambers that differed in the primary ion source and the analyzer mounting geometry. The first chamber (Argonne National Laboratory - ANL) utilizes an Atomika noble gas gun (10keV $\mathrm{Ar}^{+}$) for TOF-ISARS. This chamber was designed to allow for real-time, in situ studies of film growth processes at high ambient pressures [29]. The MSRI reflectron analyzer is mounted at a forward scattering angle of 60 degrees. The hole in the pumping aperture/extractor is $1.0 \mathrm{~mm}$ in diameter, and the aperture is positioned $44 \mathrm{~mm}$ from the sample. Differentially pumped ISS and DRS detectors as well as a Kaufman ion source and a multi-target carousel, for thin film deposition, are located on the lower half of the ANL chamber [29]. Figure 3 is a schematic of the lower half of the ANL chamber (half used for TOF-ISARS and thin film deposition). The upper half of the ANL chamber contains a double pass cylindrical mirror analyzer that is used for in situ Auger electron spectroscopy (AES), X-ray photoelectron spectroscopy (XPS), and Ultraviolet photoelectron spectroscopy (UPS) studies of the surfaces following thin film deposition. A shutter is used to isolate the two halves of this chamber. The ANL chamber was used for most of the work reported blow. The second chamber (Ionwerks - IW) uses an alkali $\left.(10 \mathrm{keV} \mathrm{K})^{+}\right)$ion source. The reflectron analyzer was mounted at a forward scattering angle $\left(\theta_{r}\right)$ of 74 degrees. The pumping aperture/extractor was $3.0 \mathrm{~mm}$ 
in diameter and was positioned $19 \mathrm{~mm}$ from the sample. The lonwerks chamber had two other DRS detectors, positioned at forward scattering angles $\left(\theta_{r}\right)$ of 15 and 30 deg as well as a Poschenreider sector MSRI analyzer located at $\theta_{1}=30 \mathrm{deg}$ [17]. The geometry of the IW chamber was such that the reflectron analyzer could be used for both MSRI and TOF-SIMS [17]. The pulsed ion beam current for both systems is less than InA, which corresponds to the arrival of $\sim 10^{9}$ ions/s.

An lonwerks, Model TDC-4 time to digital converter [30] with a digitizing resolution of 625 psec was used to collcct the TOF-ISAR spectra on both systems. This TDC allows simultaneous collection of four data channels (i.e., three DRS channels and one MSRI channel) during a single experiment.

The reflectron analyzer used for MSRI on both chambers contains six main parts: an ion extractor/pumping aperture, lens assembly, high voltage field free drift region, reflectron stack, ion detector and a neutral (line-of-sight) DRS detector [17]. For positive ion analysis, large (up to $15 \mathrm{kV}$ ) negative potentials are applied to the extractor, the lens, and the field frec drift region. The back ring potential is positive. For negative ion analysis, the potentials are inverted. Neutral species are not effected by the potentials used in the reflectron analyzer and shoot straight through to the line-of-sight detector. Below, we will show that the reflectron used for MSRI analysis can also be used for TOF-SIMS analysis when positioned at a suitable geometry (large $\theta$ ) $[17,27]$. For TOF-SIMS analysis, the potentials applied to the reflectron analyzer are optimized for low energy ion detection [17,27]. Additional details regarding the MSRI reflectron analyzer can be found elsewhere [17,27].

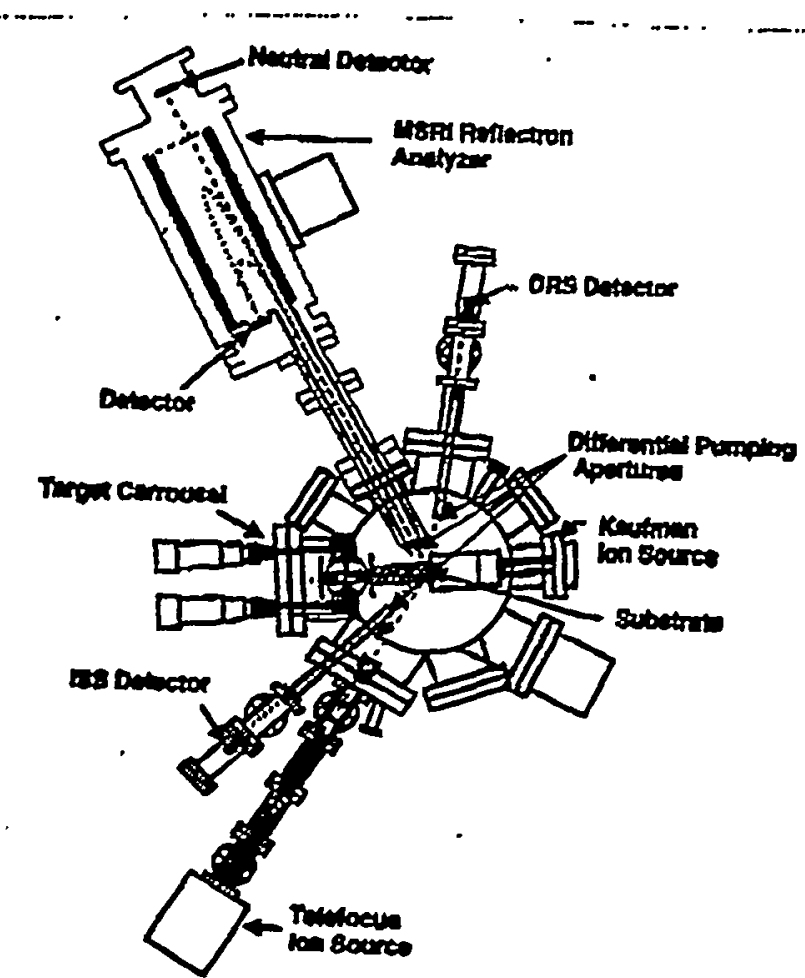

Figure 3. Lower half of the ANL chamber showing the TOF-ISARS and film growth components.

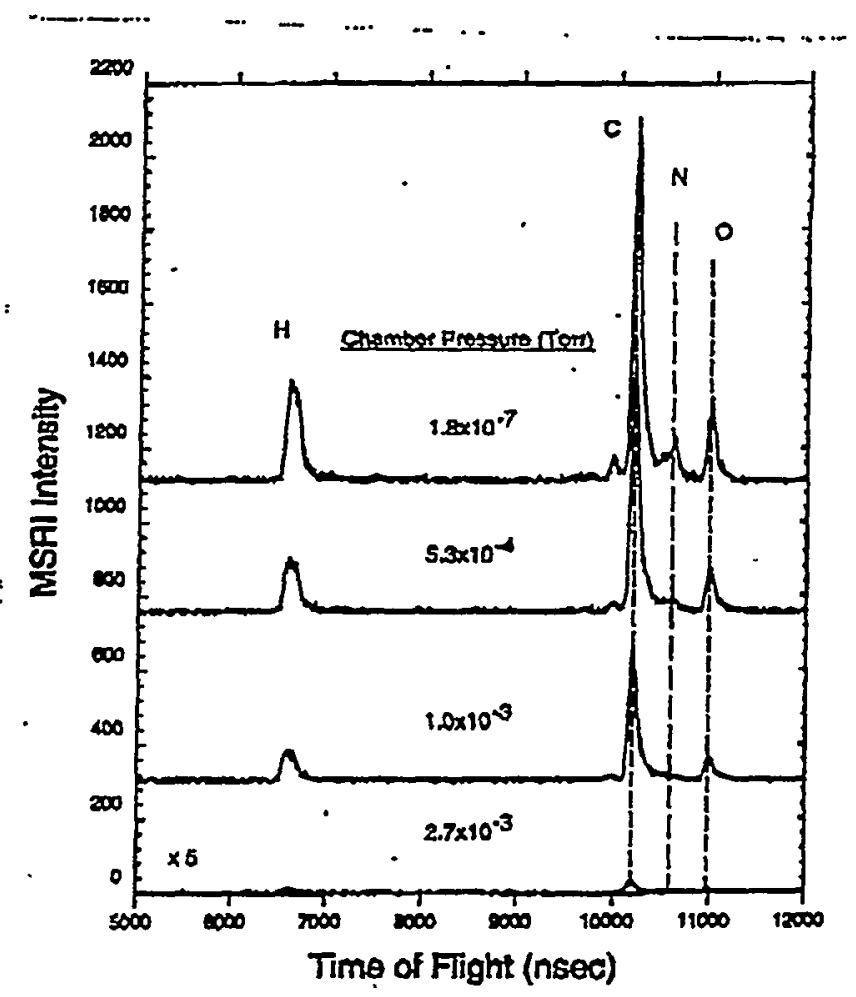

Figure 4. MSRI spectra of a dirty.Pt . sample as a function of oxygen ambient pressure. 
For a $10 \mathrm{keV}$ Ar primary ion beam and a MSRI detector position of $60 \mathrm{deg}$ (e.g., ANL MSRI configuration), the recoil energy distribution for the entire mass range, calculated from equation ( $\mathrm{l}$ ), is 0 to $2.5 \mathrm{keV}$.

\section{RESULTS AND DISCUSSION}

\section{Surface Analysis at High Ambient Pressure}

Figure 4 shows MSRI spectra obtained from a dirty $P t$ sample as a function of oxygen pressure. These spectra were obtained using 20 second data acquisition times (ANL chamber). Elsewhere, it is shown that at high ambient pressures (2.7 mTorr), the pressure in the MSRI housing is $4.8 \times 10^{-7}$ Torr; about three orders of magnitude lower [27]. As the oxygen pressure increases, the signal intensity decreases. MSRI spectra, characteristic of the surface composition, were obtained for signal to noise ratios greater than three at ambient oxygen pressures up to $-3 m$ Tor. At high ambient pressures, the loss in signal intensity is a function of both the ambient gas pressure and the high pressure path length traveled by the ion beam $(\sim 25 \mathrm{~cm})$. The product of these two quantities, $\sim 75 \mathrm{~m}$ Torr-cm, provides an upper limit for MSRI analysis $[26,27]$. If the high pressure path length could be reduced to $1 \mathrm{~cm}$, surface analysis could be performed at pressures up to $75 \mathrm{~m}$ Torr. At high ambient pressures, only the peak intensities are attenuated. Neither the peak positions, nor their lineshape, change as the pressure increases [27]. Similar effects are observed for ISS and DRS ar high ambient pressures $[25,26]$; for the ISS and DRS studies, the data collection times were typically 120 seconds (six times longer than the MSRI data collection times used in Figure 4).

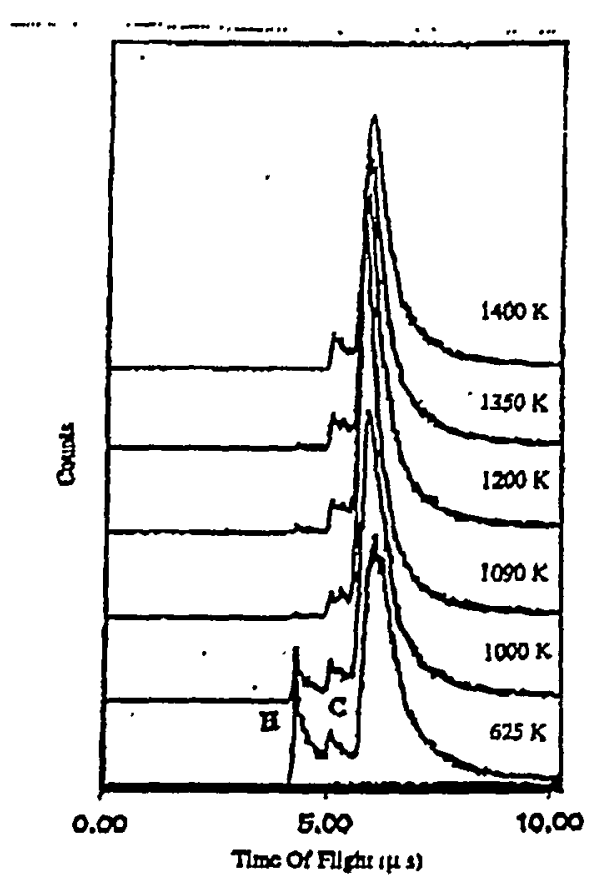

Figure 5. DR spectra of diamond as a function of heating temperature in $330 \mathrm{~m}$ Torr hydrogen with a hot filament on to produce atomic $\mathrm{H}$ [10].
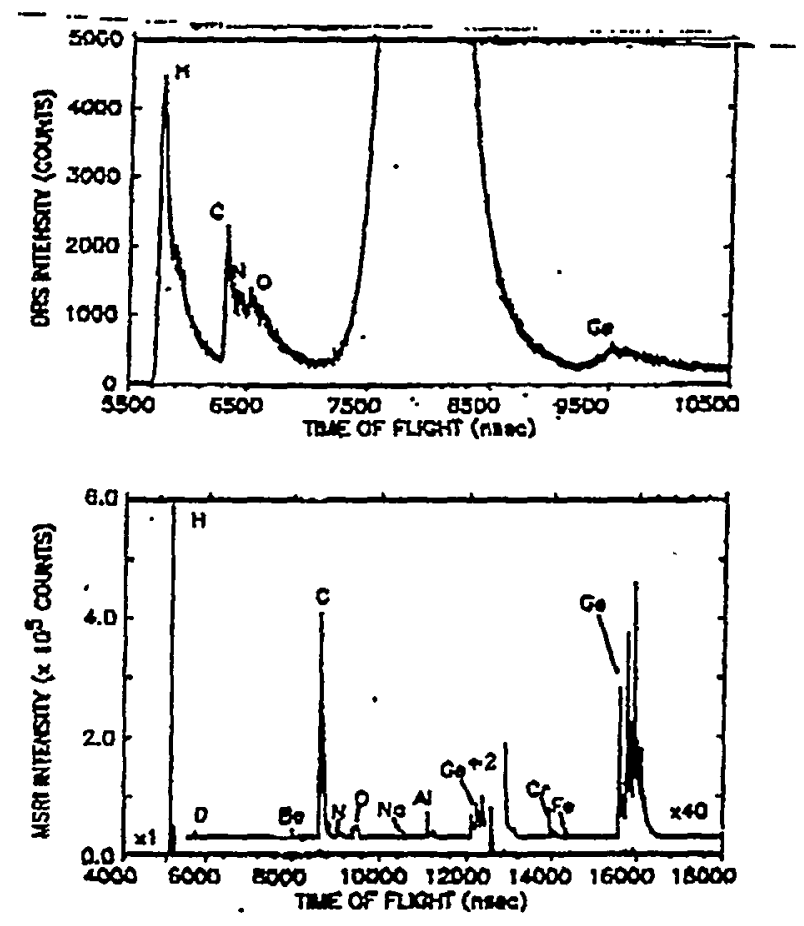

Figure 6. Simultaneously collected DRS (top) and MSRI (bottom) spectra of a dirty Ge sample [17]. 
Figure 5 shows DR spectra of a diamond surface at various heating temperatures [IO]. These spectra were obtained in a $\mathrm{H}_{2}$ ambient of 330 mTorr using a tungsten filament heated to $\sim 2300 \mathrm{~K}$ to produce activated (atomic) hydrogen. From Figure 5 , one can see that at temperatures less than $-1000 \mathrm{~K}$, hydrogen is present on the diamond surface. At temperatures above $1000 \mathrm{~K}$, the surface concentration of hydrogen starts to decrease. For temperatures above $1350 \mathrm{~K}$, hydrogen is no longer detected in the DR spectra. The DRS results shown in Figure 5 represent the first experimental measurements of the amount of hydrogen present on the diamond surface during hot filament CVD growth [10]. These data show that little, if any, hydrogen is actually present on the surface of diamond under hot filament CVD growth conditions [10]. These results have been duplicated by others [11]. It has also been shown that both $D$ and $H$ are present on diamond surfaces following atomic $D$ exposure at temperatures between $800 \mathrm{~K}$ and about $900 \mathrm{~K}$ [10]. Complete exchange of surface $\mathrm{H}$ with $\mathrm{D}$ occurred at temperatures above $1000 \mathrm{~K}$; no exchange was detected below $800 \mathrm{~K}[10]$.

The top panel of Figure 6 shows a DR spectrum of a dirty Ge sample. H, C, N, O and Ge are easily detected, however species present in trace amounts such as $\mathrm{Be}, \mathrm{Na}, \mathrm{Al}, \mathrm{Cr}$, and Fe are buried in the long tails of the dominant species [17]. The lower panel of Figure 6 shows a simultaneously collected, positive ion, MSRI spectrum [17]. Elements such as Be, $\mathrm{Al}, \mathrm{Cr}$, and $\mathrm{Fe}$ are easily identified. The spectra shown in Fjgure 6 demonstrate the enhanced resolution and sensitivity of MSRI over DRS.

\section{Real-Time, In Situ TOF-ISARS Analysis of Thin Film Deposition}

The TOF-ISARS techniques are now being used in a number of research laboratorics for real-time, in situ studies of complex multicomponent oxide thin films such as $\mathrm{Pb}\left(\mathrm{Zr}_{1-x} \mathrm{Ti}_{x}\right) \mathrm{O}_{3}(\mathrm{PZT})[29,31], \mathrm{SrBi}_{2} \mathrm{Ta}_{2} \mathrm{O}_{9}$ (SBT) [29,32], Ba. $\mathrm{Sr}_{0.5} \mathrm{TiO}_{3}$ (BST) [29], and $\mathrm{YBa}_{2} \mathrm{Cu}_{3} \mathrm{O}_{7 \times \times}$ (YBCO) [4]. In a DRS study of SBT deposition onto Pt, il was demonstrated that although $\mathrm{Pt}$ and $\mathrm{Bi}$ differ in mass by $14 \mathrm{amu}$, the resolution of DRS was not sufficient to separate these two species [32]. More recently, MSRI was used to study SBT deposition onto $\mathrm{Pt}$ and it was shown that the resolution of MSRI was sufficient to separate $\mathrm{Bi}$ (in the deposited film) from Pt (the underlying substrate) [29].

The spectra shown in Figure 7 were obtained the day the MSRI analyzer was installed onto the ANL chamber. The top panel of Figure 7 shows a positive ion MSRI spectrum of a dirty Pt sample obtained at a Xe ambient pressure of $2.2 \times 10^{-4}$ Torr. The middle panel shows a real-time, in situ MSRI spectrum of the same sample during sputter deposition (e.g., with the Kaufman ion source on). The deposition time, prior to starting the 20 second MSRI data collection, was 30 seconds. For this set of experiments, we did not have a target on the carousel, and hence, we were sputter depositing $\mathrm{Cr}$ and Fe from the stainless steel target holder. The lower panel of Figure 7 shows a MSRI spectrum of the sputter deposited film at an ambient pressure of $2.2 \times 10^{-4}$ Torr after turning off the Kaufman ion source; the total deposition time was 60 seconds. The MSRI spectra measured with the Kaufman ion source on (middle panel) and off (bottom panel) reveal similas trends; indicating that despite the increase in the background level when the ion source is on, meaningful surface analysis can be performed. These real-time, in situ MSRI spectra revealed an interesting finding. The middle and lower spectra reveal a significant amount of Mo on the substrate. The grid on the Kaufman ion source was made out of Mo. These MSRI spectra show that if the grids are not 
properly aligned, and/or if the source is not running under the proper conditions, contamination of the film, with the grid material, may occur.

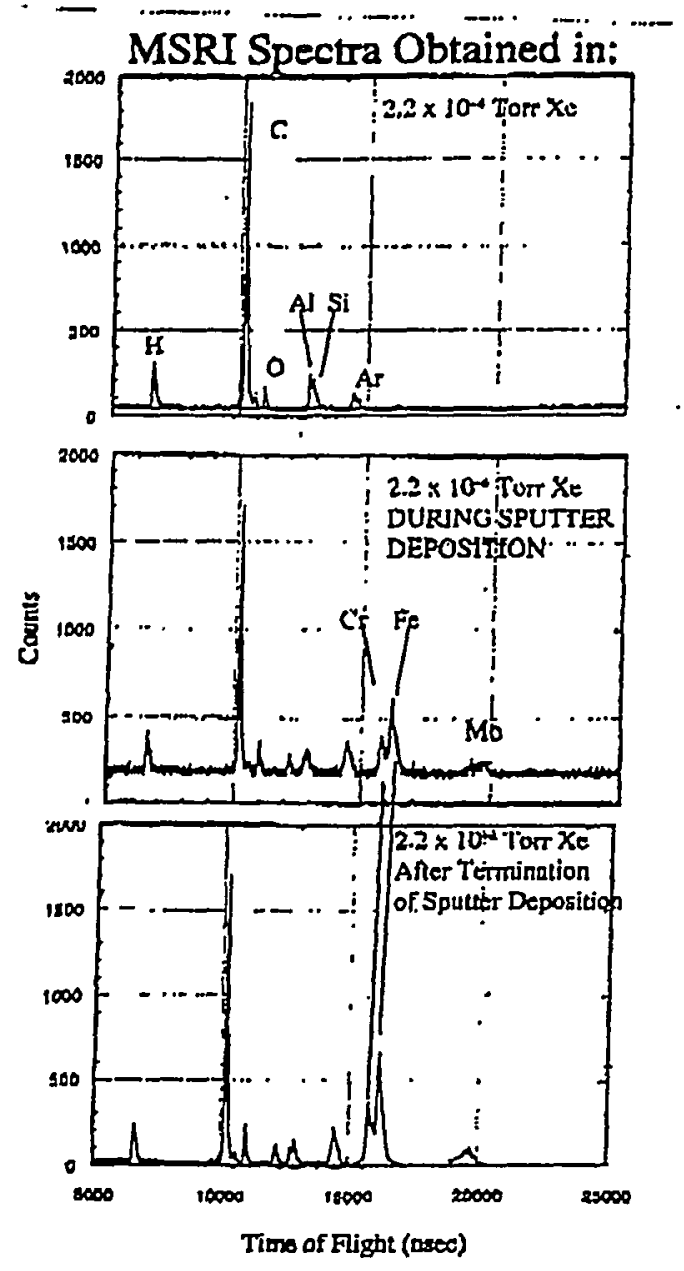

Figure 7. MSRI spectra of a dirty $\mathrm{Pt}$ sample at $2.2 \times 10^{-4}$ Torr of Xe. Before sputter deposition from a stainless steel target (top), during sputter deposition (middle), and after sputter deposition (bottom).

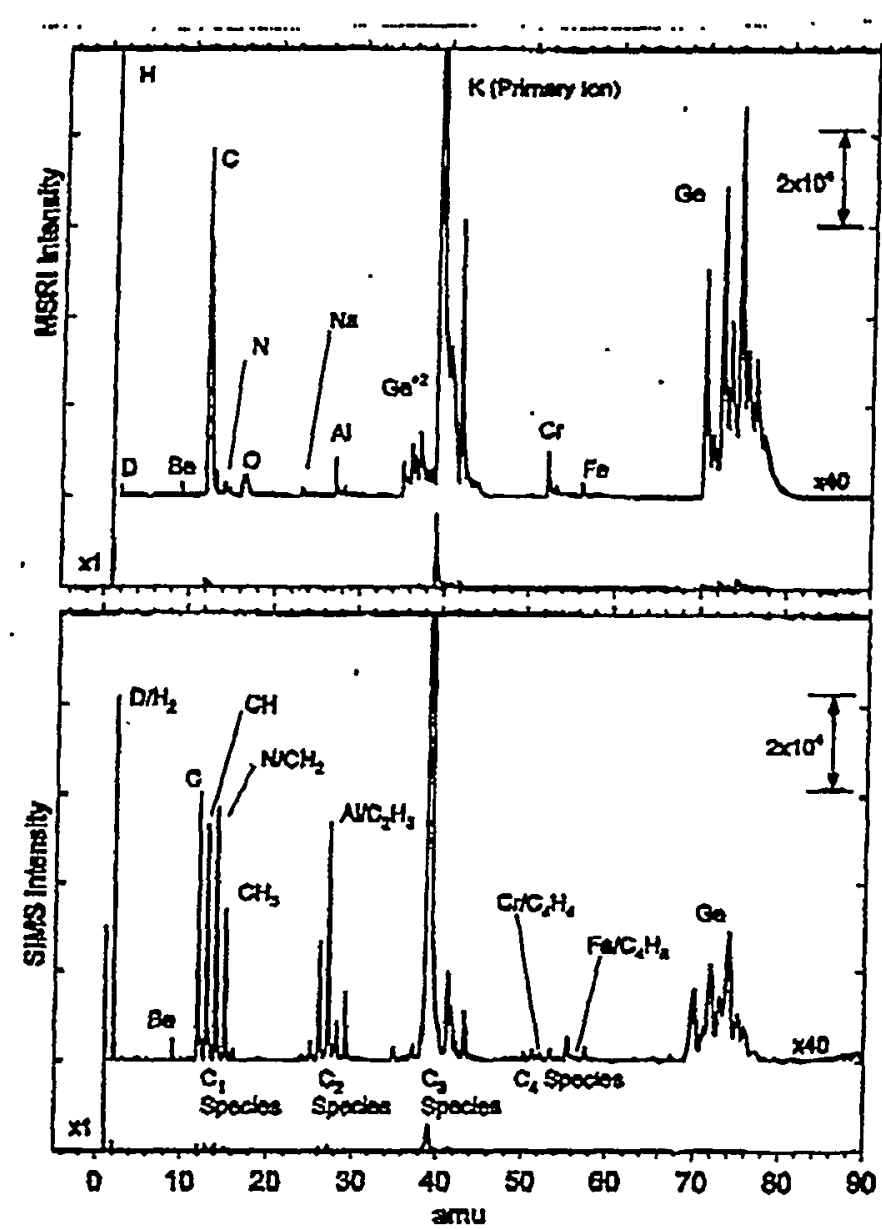

Figure 8. SIM (top) and MSRI (bottom) spectra of a dirty Ge sample. These spectra were collected back-to-back such that accurate spectral comparisons could be performed.

It is probable that for some deposition processes, real-time, in situ analysis may not be possible due to the increase in background noise. Since MSRI data acquisition can be performed at high ambient pressures in a matter of seconds, one could alternate between deposition and analysis cycles.

Others are using MSRI to monitor GaN thin film growth [33-37]. It has been shown that the $\mathrm{Ga}^{+} / \mathrm{N}^{+} \mathrm{MSRI}$ ion ratio is indicative of the film quality. If one compares the $\mathrm{Ga}^{+} / \mathrm{N}^{+}$ ion ratio measured in situ via MSRI with ex-situ photoluminescence spectra, clear trends are observed. Good films have a MSRI Ga ${ }^{+} \mathrm{N}^{+}$ion ratio of 3.0 and a photoluminescence full width at half maximum (FWHM) of $40 \mathrm{meV}$ while bad films have a MSRI Ga ${ }^{+} \mathbb{N}^{+}$ion ratio of 9.0 and a photoluminescence FWHM of $219 \mathrm{meV}$ [35]. This research group is now performing angle resolved mass spectroscopy of recoiled ion (AR-MSRD) studies during thin 
film deposition [36-37]. For AR-MSRI, one simultaneously changes both the angle of incidence of the primary ion beam $\left(\alpha_{r}\right)$ and angle of detection $\left(\theta_{r}\right)$ by rotating the sample. If one plots the locus of trajectories of each primary ion, regions behind each target atom are detected (referred to as the shadow cone) where the primary ion beam is excluded. Atoms in the "shadow cone" are not sampled by the primary ions and do not contribute to the MSRI signal. As the angles change, atoms previously located in the shadow cone may become visible. The angles where underlying species become visible can be quantitatively related to the bond distance and the bond angles for specific atomic species within the first few atomic layers. The sharpness of the onset of detection of an underlying species is related to the surface disorder; well ordered surfaces show a sharp increase while disordered surfaces show a gradual change. Therefore, in addition to the surface composition, AR-MSRI also provides the local surface structure. AR-MSRI is similar to AR-ISS $[8,9,29]$, however for the later, only elements heavier than the primary ion can be detected and the peaks are broad.

\section{Surface Phase Identification By MSRI}

Although we have focused on positive ion MSRI spectra in this manuscript, one can also measure the negative ion MSRI spectra by inverting the polarities on the reflectron analyzer. It has been demonstrated that the ratio of the positive ion to negative ion MSRI yields are characteristic of the chemical phase at the surface $[8,9,29]$. Clear distinctions have been measured for: (a) the hexagonal and cubic forms of boron nitride, (b) the different forms of carbon (e.g., graphite, diamond and amorphous carbon), and (c) the perovskite and pyrochlore phases of PZT $[8,9,29]$. Monitoring the surface composition and phase during deposition via the positive to negative ion MSRI ratio provides a simple, inexpensive, diagnostic that can be used to evaluate the properties of the growth surface; it also provides information that is needed in order to adjust the film growth conditions in order to selectively produce a desired surface phase. This type of information (coupled with process control) would allow for the unprecedented success in the growth of films that can be only be produced, with high quality, in a narrow range of growth conditions.

\section{Comparison Of MSRI And SIMS}

The reflectron analyzer was positioned at a forward scattering angle $\left(\theta_{\mathrm{r}}\right)$ of $74 \mathrm{deg}$ on the IW chamber. Using this geometry, we could selectively obtain pure MSRI or pure SIM spectra [17]. Although MSRI analysis is possible at high ambient pressures, SIMS is not - due to the low velocity of the sputtered SIMS species. The top panel of Figure 8 shows a positive ion MSRI spectrum of a dirty Ge sample, while the lower panel of Figure 8 shows a SIM spectrum. These spectra were obtained back-to-back such that a direct comparison could be made between the MSRI and SIM spectra. For SIMS analysis, the sample was rotated such that the sample normal was close to the centerline of the reflectron analyzcr, and the voltage applied to the back ring of the reflectron analyzer was lowered from $1500 \mathrm{~V}$ (for MSRI) to $50 \mathrm{~V}$ (for SIMS) $[17,27]$. The obvious difference between the MSRI and SIM spectra is the lack of molecular ions and molecular fragments in the MSRI spectrum, making the positive identification of $D, N$, $\mathrm{Al}, \mathrm{Cr}$, and $\mathrm{Fe}$ straightforward. Elemental ions as well as molecular fragments are detected in the SIM spectrum. In the SIM spectrum, one can not distinguish $\mathrm{D}$ from $\mathrm{H}_{2}$, additionally, $\mathrm{C}_{x} \mathrm{H}_{\mathrm{y}}$ fragments prevent the positive identification of $\mathrm{N}$ (vs, $\mathrm{CH}_{2}$ ), $\mathrm{O}$ (vs. $\mathrm{CH}_{4}$ ), $\mathrm{Al}$ (vs. $\mathrm{C}_{2} \mathrm{H}_{3}$ ), $\mathrm{Cr}$ (vs. 
$\mathrm{C}_{4} \mathrm{H}_{4}$ ), and $\mathrm{Fe}$ (vs. $\mathrm{C}_{4} \mathrm{H}_{8}$ ). Since the Be feature measured using MSRI and SIMS can not be attributed to any other species, a comparison of the Be MSRI and SIMS yields can be used to estimate the sensitivity of these two techniques. The observation that similar Be yields are obtained using both techniques indicates that the sensitivity for MSRI is comparable with SIMS [17]. The resolution (peak FWHM) is similar for both MSRI and SIMS for peaks with only one component - for peaks with multiple components in the SIM spectrum (i.e., 14 amu, $N$ and/or $\mathrm{CH}_{2}$ ) the resolution decreases.

The spectra shown in Figure 8 illustrate that MSRI and SIMS provide complimentary information. In MSRI, only elemental ions are detected whereas elemental ions, and molecular ions are detected in SIMS. SIMS therefore provides clues as the molecular species present on the surface. Since the MSRI ions lcave the surface with a large kinetic energy, they are not as susceptible as SIMS ions to charge neutralization with the surface. In MSRI, the ion yield varies by less than a factor of ten as the chemical state of the surface changes - simplifying quantitative analysis.

\section{CONCLUSIONS}

We have demonstrated that the three TOF-ISARS techniques (ISS, DRS and MSRI) can be used for real-time, in situ film growth studies at high ambient pressures. Selected cxamples of novel applications have been presented, focusing on the newer techniques (DRS and MSRI). Surface analysis via MSRI has a number of advantages: the ability to monitor all surface species with isotopic resolution and high sensitivity in a quantitative fashion, the ratio of the positive ion to negative ion MSRI yields are indicative of the surface phase and can be used as a process control diagnostic, the ability to perform surface analysis at high ambient pressures, and if installed at a suitable geometry, the reflectron analyzer used for MSRI can be used for TOF-SIMS. MSRI provides quantitative elemental analysis while SIMS provides clues as to the molecular specics present on the surface. MSRI and SIMS provides complimentary information that can not be obtained by either technique alone. The use of AR-MSRI to measure the local surface structure in situ and in real-time represents an exciting new area of research.

\section{ACKNOWLEDGEMENTS}

This work was supported by the U.S. Department of Energy, BES-Materials Sciences, under Contract W-31-109-ENG-38, and ER-LTR CRADA \#C9405001.

\section{REFERENCES}

[1] M. Aono, Nuclear Instruments and Methods in Physics Research B. 2, 374 (1984); J. Moller, W. Heiland, and W. Unertl, Nuclear Instruments and Methods in Physics Research B. 2, 396 (1984).

[2] C.Coudray, M. Bernheim, and G. Slodzian, Nuclear Instruments and Methods in Physics Research B. 2, 431 (1984); G. Engelmann, and E. Taglauer, Nuclear Instruments and Methods in Physics Research B. 2, 436 (1984) 
[3] D.P. Woodruff, and T.A. Delchar Modern Techniques of Surface Science (Cambridge University Press, New York, 1986) pp. 220-245.

[4] A.R. Krauss, M. Rangaswamy, Y. Lin, D.M. Gruen, J.A. Schultz, H.K. Schmidt, and R.P.H. Chang, in Multicomponent and Multilayered Thin Films for Advanced Microtechnologies: Techniques, Fundamentals and Devices, edited by 0 . Auciello, and J.Engermann (Kluwer Publishing, New York, 1993) pp.251-281

[5] W. Eckstein, Nuclear Instruments and Methods in Physics Research B. 27, 78 (1987); W. Eckstein and R. Bastasz, Nuclear Instruments and Methods in Physics Research 29, 603 (1988).

[6] T.M. Buck, in Methods of Surface Analysis, edited by A.W. Czanderna (Elsevier, Amsterdam, 1975) pp.75-100.

[7] Y.S. Chen, G.L. Miller, D.A.H. Robinson, G.H. Wheatley, and T.M. Buck, Surf. Sci. 62, 133 (1977).

[8] A.R. Krauss, O. Auciello, and J.A. Schultz, MRS Bulletin. 20 (5), 18 (1995)

[9] M.S. Hammond, J.A. Schultz, and A.R. Krauss, J. Vac. Sci. Technol. A. 13 (3), 1136 (1995)

[10] H.K. Schmidt, J.A. Schultz, and Z. Zheng, in Diamond and Diamond Like Films and Coatings, edited by R.E. Clausing, L.L. Horton, J.C. Angus, and P. Koidl (Plenum Press, New York, 1991) p. 669.

[11] A.R. Krauss, J. Im, J.A. Schultz, V.S. Smentkowski, K. Waters, C.D. Zuiker, D.M. Gruen, and R.P.H. Chang, Thin Solid Films. 270, 130 (1995).

[12] J.W. Rabalais, Science. 250, 521 (1990); CRC Crit. Rev. Solid State Mater. Sci. 14, 319 (1988).

[13] D.D. Koleske, S.M. Gates, and J.A. Schultz, J. Chem. Phys. 99 (7), 5619 (1993),

[I4] D.D. Koleske, S.M. Gates, B.D. Thoms, J.N. Russell, and J.E. Butler, Surf. Sci. 320, L105 (1994); D.D. Koleske, S.M. Gates, B.D. Thoms, J.N. Russell, and J.E. Butler, J. Chem. Phys. 102 (2), 992 (1995)

[15] W.P. Poschenrieder, Intern. J. Mass Spectrom. Ion Phys. 9, 357 (1972).

[16] V.I. Karataev, B.A. Mamyrin, and D.V. Shimikk, Sov. Phys. Tech. Phys. 16, 1177 (1972); B.A. Mamyrin, V.I. Karataev, D.V. Shmikk, and V.A. Zagulin, Sov. Phys.-JETP. 37 (1), 45 (1973).

[17] V.S. Smentkowski, A.R. Krauss, D.M. Gruen, J.C. Holecek, and J.A. Schultz, J. Vac. Sci. Technol. A. in print, 1999.

[18] K. Waters, A. Bensaoula, A. Schultz, K. Eipers-Smith, and A. Freundlich, J. of Crystal Growth. 127, 972 (1993).

[19] K. Eipers-Smith, K. Waters, and J.A. Schultz, J. of the American Cerarmic Society. 76 (2), 84 (1993).

[20] U. Diebold, J-M. Pan, and T.E. Madey, Surf. Sci. 331-333, 845 (1995); F. Pesty, H-P. Steinruck, and T.E. Madey, Surf. Sci. 339, 83 (1995); C. Dong, L. Zhang, U. Diebold, and T.E. Madey, Surf. Sci. 322, 221 (1995).

[21] Y. Wu, E. Garfunkel, and T.E. Madey, J. Vac. Sci. Technol. A. 14 (3), 1662 (1996); H.P. Steinruck, F. Pesty, L. Zhang, and T.E. Madey, Physical Review B. 51 (4), 2427 (1995).

[22] A. Benninghoven, Z.Physik 230, 403 (1970); Surf. Sci. 299/300, 246 (1994); Phys. Status Solid. 34, k169 (1969). 
[23] P. Sigmund in Sputtering by Particle Bombardment I. Springer Series Topics in Applied Physics Vol 47, edited by R. Behrisch (Springer Verlag: Berlin and Heidelberg, 1981) p27.

[24] H. D. Hagstrum, Phys. Rev. 96 (2), 336 (1954).

[25] Y. Lin, A.R. Krauss, R.P.H. Chang, O.H. Auciello, D.M. Gruen, and J.A. Schultz, Thin Solid Films. 253, 247 (1994).

[26] J. Im, A.R. Krauss, Y. Lin, J.A. Schultz, O.H. Auciello, D.M. Gruen, and R.P.H. Chang, Nuclear Instruments and Methods in Physics Research B. 118, 772 (199).

[27] V.S. Smentkowski, J.C. Holecek, J.A. Schultz, A.R. Krauss, and D.M. Gruen, in Secondary Ion Mass Spectrometry, SIMS XI, edited by G.Gillen, R. Lareau, J. Bennett, and F. Stevie (John Wiley and Sons, New York, 1997) p.1083.

[28] A.V. Phelps, J. Phys. Chem. Ref. Data. 20, 557 (1991).

[29] A.R. Krauss, J. Im, V.S. Smentkowski, J.A. Schultz, O. Auciello, D.M. Gruen, J. Holecek, and R.P.H. Chang, Materials Science and Engineering A. 253, 221 (1998).

[30] Ionwerks, 2472 Bolsover, Suite 255, Houston, Texas 77005, te1: 713-522-9880, fax: 713522-6735, http://www.ionwerks.com

[31] A.R. Krauss, Y. Lin, O. Auciello, G.J. Lamich, D.M. Gruen, J.A. Schultz, and R.P.H. Chang, J. Vac. Sci. Technol. A. 12 (4), 1943 (1994).

[32] O. Auciello, A.R. Krauss, J. Im, D.M. Gruen, E.A. Irene, R.P.H. Chang, and G.E. McGuire, Appl. Phys. Lett. 69 (18), 2671 (1996).

[33] E. Kim, A. Bensaoula, I. Rusakova, A. Schultz, and K. Waters, Mat. Res. Soc. Symp. Proc. 449, 318 (1997).

[34] E.Kim, I. Berishev, A. Bensaoula, S. Lee, S.S. Perry, K. Waters, and J.A. Schultz, Appl. Phys. Lett. 71, 21 (1997); E. Kim, I. Berishev, A. Bensaoula, I. Rusakova, KI. Waters, and J.A. Schultz, J. Appl. Phys. 85, 1178 (1999).

[35] A. Bensaoula, I. Rusakova, J.A. Schultz, and K. Waters, in III-V Nitrides, edited by T. Moustakas, B. Monemar, I. Akasaki, F, Ponce, (Mater. Res. Soc. Proc. 449, Pittsbrugh, PA, 1997) pp. 319; E. Kim, I. Berishev, A. Bensaoula, J.A. Schultz, K. Waters, and W.Zagozdzon-Wosik, MRS Intemet Joumal of Nitride Semiconductor Research, 3, 22 (1998); http://nsr.mij.mrs.org/3/22/

[36] A. Bensaoula, presented at the 1999 MRS Spring Meeting (Symposium U, talk U1.2), San Francisco, CA, 1999 (unpublished).

[37] A. Bensaoula, presented at the 45 International Meeting of the AVS, Baltimore, MA, . 1998 (in press - spring/summer 1999). 